\title{
Acceptance and Use of Information System: E-Learning Based on Cloud Computing in Vietnam
}

\author{
Thanh D. Nguyen ${ }^{1}$, Dung T. Nguyen ${ }^{1}$, and Thi H. $\mathrm{Cao}^{2}$ \\ ${ }^{1}$ HCMC University of Technology, Vietnam \\ \{thanh.nguyenduy, dung.nguyentien090\} @gmail.com \\ ${ }^{2}$ Saigon Technology University, Vietnam \\ thi.caohao@stu.edu.vn
}

\begin{abstract}
E-learning is an inevitable trend of education in the future. Although there are several researches about E-learning based on cloud computing, not many researches on the cloud computing adoption model, on the other hand, there are not many studies on the adoption of cloud-based E-learning in Vietnam and in the World. This study adapts the extended of Unified Theory of Acceptance and Use of Technology (UTAUT2) [48] to research the acceptance and use of E-learning based on cloud computing in Vietnam. These elements, namely facilitating condition, performance expectancy, effort expectancy, social influence, hedonic motivation, price value and habit influence on the intention and use of cloud-based E-Learning, the results show that seven out of eleven hypotheses are supported. The results will help implementing E-learning based on cloud and learning strategies to be more successful.
\end{abstract}

Keywords: Adoption, cloud computing, E-learning, factors, UTAUT.

\section{Introduction}

In contemporary society, the learning process is becoming a vital factor in business and socioeconomic growth [22]. The first E-learning (E-L) courses were launched in 1998. Since then E-L business has gone global and the competition is fierce. Now, $70 \%$ of E-L takes place in the United State and Europe, but Asia Pacific is catching up fast, with Vietnam and Malaysia grow the fastest [9]. According to Ambient Insight [6], Vietnam is ranked $\left(1^{\text {st }}\right)$ within the top ten countries in the world in terms of high-growth in E-L revenues over the next few years (2011-2016), the VN projected growth rate in E-L of $44.3 \%$. Vietnam Government and Ministry of Education and Training effort to introduce content digitalisation in school systems ${ }^{*}$, a large expansion of online higher education possibilities and a growing demand for E-L in the corporate sector will drive the educational growth. Recently, cloud computing (CC) has changed the nature of internet from the static environment to a highly dynamic environment, which allows users to run software applications collaborate, share

\footnotetext{
* Vietnam Ministry of Education and Training had guided the deployment of information technology task for the academic year of 2011-2012, dispatch no. 4960/BGDĐT-CNTT.
}

The original version of this chapter was revised: The affiliation of Thanh D. Nguyen and Dung T. Ngyuen was corrected. An erratum to this chapter can be found at https://doi.org/10.1007/978-3642-55032-4_72 
information, create application virtual, learn online... According to Venkatraman [49], moving its E-L to CC platform, Marconi University (Italy) has achieved cost savings and financial flexibility. It is $23 \%$ cheaper to run in a year than the previous solution.

Although there are several researches about cloud-based E-learning (CBE-L), not many researches on the $\mathrm{CC}$ adoption model. On the other hand, there are not many studies on the adoption of CBE-L in Vietnam and also in the World. Based on the review of the literature, Unified Theory of Acceptance and Use of Technology (UTAUT) [47], and UTAUT2 [48], the model of Acceptance and Use of E-Learning based on cloud computing in Vietnam is proposed.

\subsection{Background}

E-L is one of the most famous technologies discovered to make the traditional way of education, learning easier, with the help of software applications and virtual learning environment. According to Tavangarian and et al. [41], E-L includes numerous types of media that deliver text, audio, images, animation, streaming video. It includes technology applications and processes such as audio, video, satellite TV, and computer-based learning as well as local intranet or extranet, and web-based learning. Information and communication systems, whether freestanding, based on either local networks or the Internet in networked learning, underlies many E-L processes.

$\mathrm{CC}$ is one of the popular buzzword used all over the information technology world. The CC term is actually derived from the way the Internet is often signified in network diagrams $[34,35]$. Based on the different virtual levels, CC is typically divided into 3 types according to the packaging of computing resources in different abstraction layers, these are Infrastructure as a Service (IaaS), Platform as a Service (PaaS) and Software as a Service (SaaS) [39]. According to Zheng and Jingxia [55], CBE-L services can be divided into 4 types as described in Table 1 .

Table 1. Types of content and cloud computing services

\begin{tabular}{lll}
\hline & Content & Cloud \\
\hline 1 & Standard data, audio, video, data, images, text... & IaaS \\
2 & Data can be converted into standard data content & SaaS \\
3 & Web-based proprietary data, player embedded in web pages... & SaaS \\
4 & Private defined data, player needs to download manually... & PaaS \\
\hline
\end{tabular}

Source: Zheng and Jingxia. [55]

\section{Research Model}

\subsection{Literature Review}

Technology acceptance has been examined extensively in the research of information system. Most of the studies associated in the analysis of behavioral intention that is conscious of user decision to accept technology. Several theories were developed to explain the phenomena from different research. Theory of Reasoned Action (TRA) was researched in psychosocial perspective in order to identify elements of the 
trend-conscious behavior $[5,17]$. Theory of Planned Behavior (TPB) was constructed by Ajzen [1, 2, 3] from the original TRA theory and added perceived behavioral control element. Technology Acceptance Model (TAM) based on the theoretical foundation of the TRA to establish relationships between variables to explain human behavior regarding acceptance of information systems [12, 13]. Innovation Diffusion Theory (IDT) explained the process of technological innovation that is accepted by users [36].

Unified Theory of Acceptance and Use of Technology (UTAUT) had been built by Venkatesh et al. [47] to explain intention and use behavior of information system users. UTAUT model was developed through theoretical models as TRA [5, 17], TPB $[1,2,3]$; TAM [12, 13], integrated mode of TPB and TAM [42], IDT [31], Motivation Model (MM) [14], Model of PC Utilization (MPCU) [43] and Social Cognitive Theory (SCT) $[11,21]$. UTAUT was formulated with 4 core elements of intention and use as performance expectancy, effort expectancy, social influence and facilitating condition. Venkatesh et al. [48] adopted an approach that complements the original constructs in UTAUT, called UTAUT2, which had been integrated hedonic motivation, price value and habit factors into UTAUT. Also, demographic variables such as age, gender and experience - drop voluntariness, which is part of the original UTAUT.

Although there are many researches about E-L based on CC platform which were researched by Zaharescu [53]; Manop [29]; Deepanshu et al. [15]; Bhruthari et al. [7]; Masud and Huang [30]; Viswanath et al. [51]; Zheng and Jingxia [55]; Utpal and Majidul [44]... there are not many researches on the CC adoption model such as Leonardo et al. [25]; Muhambe and Daniel [32]; the studies of E-L acceptance and usage had been researched by Sun et al. [40]; Will and Allan [52]; Soud and Fisal [38]; Lin et al. [28]... On the other hand, there are not many researches on the acceptance and use of CBE-L in Vietnam and also in the world.

\subsection{Theoretical Framework}

Based on the review of the literature, Unified Theory of Acceptance and Use of Technology (UTAUT) [47], and UTAUT2 [48], the model of Acceptance and Use of ELearning based on cloud computing in Vietnam is built in Fig. 1. The following are theoretically supported and resulting hypotheses that elicit relationships in the model.

Facilitating Condition $(F C)$ is the degree to which an individual believes that an organizational and technical infrastructure exists to support the use of the system. This definition captures concepts embodied by 3 different constructs on perceived behavioral control in TPB [1, 2, 3]; TAM [12, 13], facilitating condition in MPCU [43], and compatibility in IDT [31,36]. Venkatesh [45] found support for full mediation of the effect of facilitating condition on intention and usage by effort expectancy. According to Will and Allan [52], there are all sorts of problems involved in using an E-L system because of hardware, software and support. Thus, under CBE-L in Vietnam, it hypothesizes that:

Hypothesis $H 1_{a}$ : FC has a positive effect on CBE-L intention (CEI).

Hypothesis $H 2_{a}$ : FC has a positive effect on CBE-L usage (CEU).

Performance Expectancy $(P E)$ means that an individual believes that using the system will help them to attain gains in job performance. The five constructs from the 
different models that pertain to performance expectancy are perceived usefulness in TAM [12, 13]; TAM 2 [46], extrinsic motivation in MM [14], job-fit in MPCU [43], relative advantage in IDT [31, 36], and outcome expectations in SCT $[11,21]$. The learner believed that the E-L system was helpful to their performance and the individual learner would be more satisfied with the E-L [52]. Thus, under CBE-L in Vietnam, it hypothesizes that:

Hypothesis $\mathrm{H}_{b}$ : PE has a positive effect on CEI.

Effort Expectancy $(E E)$ indicates that the degree of ease associated with the use of the system. Three constructs from the existing models capture the concept of effort expectancy as perceived ease of use in TAM [12, 13]; TAM 2 [46], complexity in MPCU [43], and ease of use in IDT [31, 36]. The effort expectancy of an E-L system would influence users in their deciding whether or not to use the system [52]. Thus, it hypothesizes that:

Hypothesis $H 1_{c}$ : EE has a positive effect on CEI.

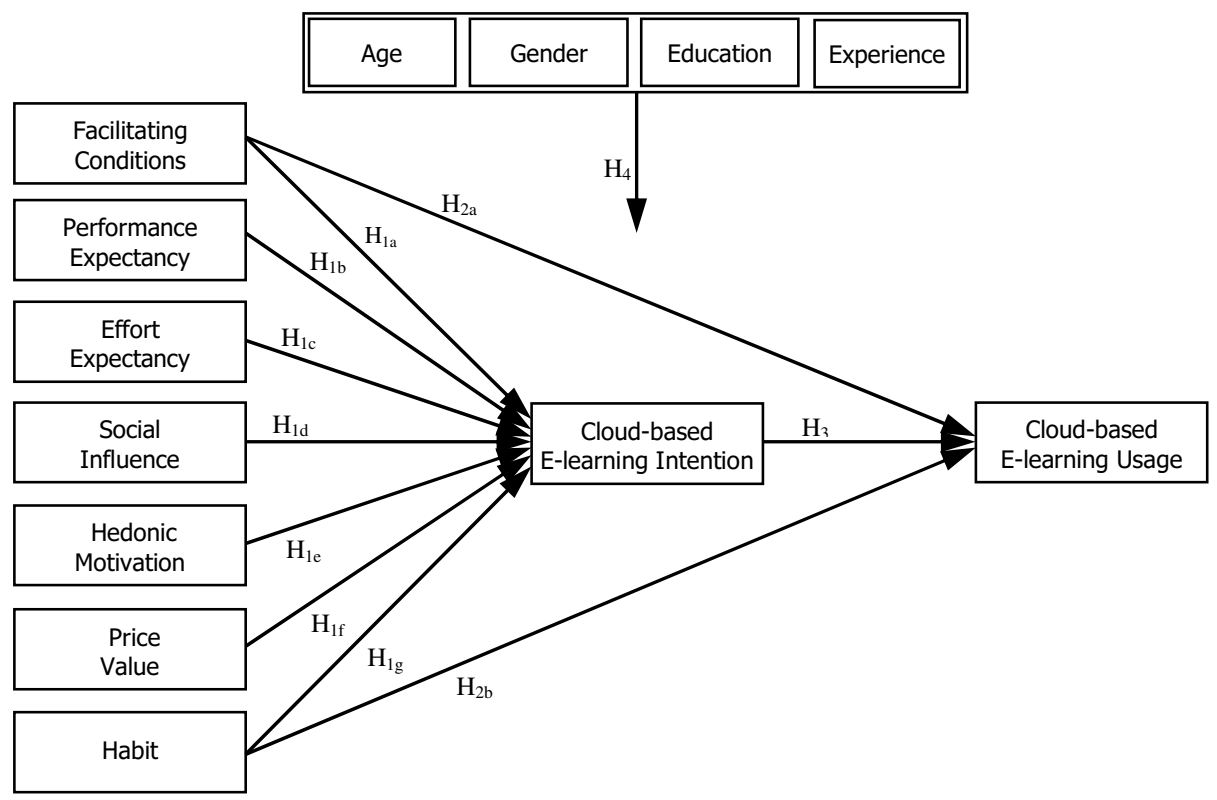

Fig. 1. Research Model: Acceptance and Use of E-learning based on Cloud Computing (Source: Adapted from UTAUT2 [48])

Social Influence (SI) is defined as the degree to which an individual perceives that important others believe people should use the new system. Social influence as a direct determinant of behavioral intention is represented as subjective norm in TRA [5, 17]; TAM [12, 13]; TAM 2 [46], social elements in MPCU [43], and image in IDT [31], [36]. According Venkatesh et al. [47], the role of social influence in technology acceptance decisions is complex and subject to a wide range of contingent influences. Will and Allan [52] noted that individual learners also recognized the fact that there might be a lot of problems in the E-L process. Thus, it hypothesizes that: 


\section{Hypothesis HId: SI has a positive effect on CEI.}

Hedonic Motivation (HM) has been the fun or pleasure derived from using a technology, and it has been shown to play an important role in determining technology acceptance and use [8]. In information system research, such hedonic motivation has been found to influence the technology acceptance and use directly [20]. According to Childers et al. [10]; Brown and Venkatesh [8], in the consumer context, hedonic motivation has also been found to be an important determinant of technology acceptance and use. Thus, it hypothesizes that:

Hypothesis HIe: HM has a positive effect on CEI.

Price Value $(P V)$ means the cost and pricing structure may have a significant impact on the consumer technology user. The monetary cost and price is usually conceptualized together with the quality of products or services to determine the perceived value of products or services [54]. Dodds et al. [16] defined the price value as a consumer cognitive tradeoff between the perceived benefits of the applications and the monetary cost for using them. According to Venkatesh et al. [48], the price value is positive when the benefits of using a technology are perceived to be greater than the monetary cost, and such price value has a positive impact on intention. Thus, it hypothesizes that:

Hypothesis HIf: PV has a positive effect on CEI.

Habit (HA) has been defined as the extent to which people tend to perform behaviors automatically because of learning and equate habit with automaticity [23, 27]. Ajzen and Fishbein [4] noted that feedback from previous experiences influence various beliefs and consequently, future behavioral performance. According to Venkatesh et al. [48], the role of habit in technology use has delineated different underlying processes by which habit influences technology use. Thus, it hypothesizes that:

Hypothesis HIg: Habit has a positive effect on CEI.

Hypothesis H2b: Habit has a positive effect on use CEU.

$C B E-L$ Intention (CEI), consistent with the underlying theory for all of the intention models are reviewed in studies such as Sheppard et al. [37]; Venkatesh et al. [47]; Venkatesh et al. [48] for literature review of the intention-behavior relationship, so that behavioral intention has a significant positive influence on technology usage. Thus, under CBE-L in Vietnam, it hypothesizes that:

Hypothesis H3: CEI has a positive effect on CEU.

Demographic (DE), including age, gender, experience and voluntariness were suggested as part of UTAUT [47], and were included in the analysis. They were analyzed to find out how they influenced the acceptance elements, including performance expectancy, effort expectancy, social influence and facilitating condition towards intention and use. According to Venkatesh et al. [48], in UTAUT2 model, voluntariness has been dropped in part of the original UTAUT. Thus, under CBE-L in Vietnam, it hypothesizes that:

Hypothesis H4: Independent and dependent elements are influenced by DE.

\section{$3 \quad$ Research Results}

\subsection{Data}

Data collection was undertaken by a survey using convenient sampling. The questionnaires were sent to respondents on google docs, via email, E-L forums, and sent 
hard copy questionnaires to respondents who have used or intend to use CBE-L in Vietnam. A total of 320 respondents was obtained, of which 282 were usable (38 invalid respondents). All scales were in the form of five-point Likert [26] scale with 29 observed variables. The data were analyzed by Structural Equation Modeling (SEM) techniques with the application of SPSS and AMOS.

Table 2. All variables of the research model in factor analysis

\begin{tabular}{|c|c|c|c|c|}
\hline & & & \multicolumn{2}{|c|}{ Factor loading } \\
\hline & & & EFA & CFA \\
\hline \multirow{3}{*}{ FC } & \multicolumn{4}{|c|}{$\alpha=0.685 ;$ AVE $=0.549$} \\
\hline & $\mathrm{FC}_{1}$ & The resources necessary to use CBE-L & 0.913 & .890 \\
\hline & $\mathrm{FC}_{3}$ & Knowledge necessary to use CBE-L & 0.724 & 0.615 \\
\hline \multirow{5}{*}{$\mathrm{PE}$} & \multicolumn{4}{|c|}{$\alpha=0.830 ;$ AVE $=0.520$} \\
\hline & $\mathrm{PE}_{3}$ & CBE-L useful in job & 0.839 & 0.771 \\
\hline & $\mathrm{PE}_{2}$ & Using CBE-L enables to accomplish tasks quickly & 0.820 & 0.758 \\
\hline & $\mathrm{PE}_{1}$ & Using CBE-L increases productivity & 0.789 & 0.684 \\
\hline & $\mathrm{PE}_{4}$ & Increase chances of getting a raise & 0.786 & 0.675 \\
\hline \multirow{5}{*}{$\mathrm{EE}$} & \multicolumn{4}{|c|}{$\alpha=0.784 ;$ AVE $=0.589$} \\
\hline & $\mathrm{EE}_{3}$ & Learning how to use CBE-L is easy & 0.840 & .868 \\
\hline & $\mathrm{EE}_{2}$ & Interaction with CBE-L is clear and understandable & 0.786 & .754 \\
\hline & $\mathrm{EE}_{4}$ & Finding CBE-L easy to use & 0.775 & .716 \\
\hline & $\mathrm{EE}_{1}$ & It is easy to become skillful at using CBE-L & 0.772 & .666 \\
\hline \multirow{4}{*}{ SI } & \multicolumn{4}{|c|}{$\alpha=0.740 ;$ AVE $=0.535$} \\
\hline & $\mathrm{SI}_{1}$ & People are important to think that should use EL & 0.797 & 0.792 \\
\hline & $\mathrm{SI}_{2}$ & People influence behavior think that should use EL & 0.783 & 0.760 \\
\hline & $\mathrm{SI}_{3}$ & People whose opinions that value prefer use EL & 0.650 & 0.637 \\
\hline \multirow{4}{*}{$\mathrm{HM}$} & \multicolumn{4}{|c|}{$\alpha=0.807 ;$ AVE $=0.584$} \\
\hline & $\mathrm{HM}_{1}$ & Using CBE-L is fun & 0.813 & 0.792 \\
\hline & $\mathrm{HM}_{3}$ & Using CBE-L is enjoyable & 0.754 & 0.778 \\
\hline & $\mathrm{HM}_{2}$ & Using CBE-L is entertaining & 0.728 & 0.718 \\
\hline \multirow{3}{*}{ PV } & \multicolumn{4}{|c|}{$\alpha=0.784 ;$ AVE $=0.520$} \\
\hline & $\mathrm{PV}_{3}$ & CBE-L is a good value for the money & 0.857 & .641 \\
\hline & $\mathrm{PV}_{2}$ & At the current price, CBE-L provides a good value & 0.849 & 0.628 \\
\hline \multirow{4}{*}{ HA } & \multicolumn{4}{|c|}{$\alpha=0.804 ; \mathrm{AVE}=0.607$} \\
\hline & $\mathrm{HA}_{2}$ & Using CBE-L has become a habit & 0.892 & 0.871 \\
\hline & $\mathrm{HA}_{3}$ & Addicted to use CBE-L & 0.804 & 0.791 \\
\hline & $\mathrm{HA}_{1}$ & Must use CBE-L & 0.660 & 0.647 \\
\hline \multirow{4}{*}{ CEI } & \multicolumn{4}{|c|}{$\alpha=0.822 ; \mathrm{AVE}=0.523$} \\
\hline & $\mathrm{CEI}_{2}$ & Intend to use CBE-L in the future & 0.862 & 0.779 \\
\hline & $\mathrm{CEI}_{3}$ & Will try to use CBE-L in daily life & 0.858 & 0.713 \\
\hline & $\mathrm{CEI}_{1}$ & Will plan to use CBE-L frequently & 0.857 & 0.642 \\
\hline \multirow{3}{*}{ CEU } & \multicolumn{4}{|c|}{$\alpha=0.805 ;$ AVE $=0.612$} \\
\hline & $\mathrm{CEU}_{1}$ & Intend to use CBE-L in the next 1 months & 0.919 & 0.787 \\
\hline & $\mathrm{CEU}_{2}$ & Plan to use CBE-L in the next 3 months & 0.902 & 0.778 \\
\hline
\end{tabular}

$\alpha$ : Cronbach alpha; AVE: Average Variance Extracted. 
A descriptive statistic is conducted for indicators related to the users who have used cloud-based E-learning. Gender: there are approximately $64 \%$ male and $36 \%$ female, it is uneven. Age: as regards the 19 - 23 age group, 24 - 30 group, and older30 group, the former is by far the highest at nearly $50 \%$, followed by the latter at $27 \%$ and $21 \%$ respectively. Education: there are nearly $70 \%$ of E-learners in university degree, about $24 \%$ of E-learners in post-graduated degree and percentage of the other is low. Experience: although about $60 \%$ of the people who are good at computing, only about $1 \%$ people are bad at computing, $39 \%$ average experience in computer using. Therefore, most of people have experienced in computing. Cloud computing: similarities exist between google drive, and modify where roughly $32 \%$ respondents use CC, $20 \%$ use dropbox, $13 \%$ use sky drive...

\subsection{Exploratory and Confirmatory Factor Analysis}

After eliminating 1 item that is $F C_{4}$ of facilitating condition element in reliability analysis (Cronbach alpha) due to the correlation-item of $F C$ factor $<0.60$ [33]. The composite reliability of constructs ranges from 0.685 to 0.830 . Eliminating 2 items these are $P V_{1}$ and $F C_{3}$ of price value and facilitating condition elements in the $1^{\text {st }} \mathrm{Ex}-$ ploratory Factor Analysis (EFA) due to the factor loading $<0.50$ [19]. The $2^{\text {nd }}$ EFA and then Confirmatory Factor Analysis (CFA) are conducted to assess and refine the measurement scales. The CFA on the overall measurement model yields the following measures: Chi-square $\left(\chi^{2}\right) / \mathrm{dF}=1.928 ; \mathrm{p}=0.000$; $\mathrm{TLI}=0.901 ; \mathrm{CFI}=0.917$; RMSEA $=0.054$. The CFA loading of all items ranges from 0.602 to 0.879 . The Average Variance Extracted (AVA) of constructs ranges from 0.520 to $0.612(>0.50)$ which are good scales [18]. Therefore, the measurement scales for all constructs are satisfactory. The results of factor analysis are shown in Table 2.

Table 3. Analysis of hypothesized relationships $\left(\mathrm{H} 1_{\mathrm{x}}, \mathrm{H} 2_{\mathrm{y}}\right.$ and $\left.\mathrm{H} 3\right)$

\begin{tabular}{|c|c|c|c|c|c|c|c|c|}
\hline \multicolumn{2}{|r|}{$\mathrm{H}$} & \multicolumn{3}{|c|}{ Relationships } & \multirow{2}{*}{$\begin{array}{c}\text { Estimate } \\
0.113\end{array}$} & \multirow{2}{*}{$\begin{array}{r}\text { S. E. } \\
0.091\end{array}$} & \multirow{2}{*}{$\frac{\mathrm{p} \text {-value }}{0.076}$} & \multirow{2}{*}{$\frac{\text { Result }}{\text { Rejected }}$} \\
\hline 1 & $\mathrm{H} 1_{\mathrm{a}}$ & $\mathrm{FC}$ & $\rightarrow$ & CEI & & & & \\
\hline 2 & $\mathrm{H} 1_{\mathrm{b}}$ & PE & $\rightarrow$ & CEI & 0.137 & 0.057 & 0.027 & Supported \\
\hline 3 & $\mathrm{H} 1_{\mathrm{c}}$ & $\mathrm{EE}$ & $\rightarrow$ & CEI & 0.071 & 0.050 & 0.220 & Rejected \\
\hline 4 & $\mathrm{H} 1_{\mathrm{d}}$ & SI & $\rightarrow$ & CEI & 0.348 & 0.065 & $* * *$ & Supported \\
\hline 5 & $\mathrm{H} 1_{\mathrm{e}}$ & $\mathrm{HM}$ & $\rightarrow$ & CEI & 0.568 & 0.059 & $* * *$ & Supported \\
\hline 6 & $\mathrm{H} 1_{\mathrm{f}}$ & PV & $\rightarrow$ & CEI & 0.154 & 0.438 & 0.689 & Rejected \\
\hline 7 & $\mathrm{H} 1_{\mathrm{g}}$ & HA & & CEI & 0.201 & 0.038 & $* * *$ & Supported \\
\hline 8 & $\mathrm{H} 2_{\mathrm{a}}$ & $\mathrm{FC}$ & $\rightarrow$ & CEU & 0.071 & 0.088 & 0.220 & Rejected \\
\hline 9 & $\mathrm{H} 2_{\mathrm{b}}$ & HA & $\rightarrow$ & CEU & 0.129 & 0.047 & 0.048 & Supported \\
\hline 10 & $\mathrm{H} 3$ & CEI & $\rightarrow$ & CEU & 0.841 & 0.093 & $* * *$ & Supported \\
\hline
\end{tabular}

$\mathrm{x}: \mathrm{a}, \mathrm{b}, \mathrm{c}, \mathrm{d}, \mathrm{e}, \mathrm{d}, \mathrm{e}, \mathrm{f}, \mathrm{g} ; \mathrm{y}: \mathrm{a}, \mathrm{b}, \mathrm{c} ;{ }^{* * *} \mathrm{p}<0.001$. 


\subsection{Structural Model}

The estimation of structural model was then conducted using ML estimation. The indexes for the model showed adequate fit with $\chi^{2} / \mathrm{dF}=1.768 ; \mathrm{p}=0.000$; TLI=0.918; $\mathrm{CFI}=0.931$; RMSEA $=0.048$. The standardized path coefficients presented in Table 3: Support the positive effect of $P E$ on $C E I$ with $\gamma=0.137(\mathrm{p}=0.027)$, that supports $\mathrm{H} 1_{\mathrm{b}}$. SI and $H M$ have strongly positive effect on $C E I$ with $\gamma=0.348(\mathrm{p}<0.001)$ and $0.568(\mathrm{p}<0.001)$, which in turn $\mathrm{H} 1_{\mathrm{d}}$ and $\mathrm{H} 1_{\mathrm{e}}$ are supported. Support the positive effect of $H A$ on $C E I$ and $C E U$ with $\gamma=0.201(\mathrm{p}<0.001)$ and $0.129(\mathrm{p}=0.040)$, which support $\mathrm{H} 1_{\mathrm{g}}$ and $\mathrm{H} 2_{\mathrm{b}}$. However, the path from $F C, E E$ and $P V$ to $C E I$ and from $F C$ to $C E U$ are non-significant at $\mathrm{p}=0.05$. Therefore, $\mathrm{H} 1_{\mathrm{a}}, \mathrm{H} 1_{\mathrm{c}}, \mathrm{H} 1_{\mathrm{f}}$ and $\mathrm{H} 2_{\mathrm{a}}$ are rejected. Moreover, the results support $\mathrm{H} 3$ by showing a strong impact of $C E I$ on $C E U$ with $\gamma=$ $0.841(\mathrm{p}<0.001)$.

Table 4. ANOVA analysis follow age, gender, education and experience (H4)

\begin{tabular}{lcccccccccc}
\hline Demographic & FC & PE & EE & SI & HM & PV & HA & CEI & CEU & Note \\
\hline Age & $\mathrm{x}^{* *}$ & $\mathrm{x}^{* *}$ & - & $\mathrm{x}^{*}$ & $\mathrm{x}^{*}$ & - & $\mathrm{x}^{*}$ & - & - & 5 elements \\
Gender & $\mathrm{x}^{*}$ & $\mathrm{x}^{* *}$ & $\mathrm{x}^{* * *}$ & $\mathrm{x}^{*}$ & - & - & $\mathrm{x}^{*}$ & $\mathrm{x}^{*}$ & - & 6 elements \\
Education & - & $\mathrm{x}^{*}$ & $\mathrm{x}^{*}$ & $\mathrm{x}^{* *}$ & $\mathrm{x}^{* *}$ & - & $\mathrm{x}^{*}$ & - & - & 5 elements \\
Experience & $\mathrm{x}^{* * *}$ & - & $\mathrm{x}^{*}$ & - & $\mathrm{x}^{*}$ & - & - & - & - & 3 elements \\
\hline
\end{tabular}

$\mathrm{x}$ : individual differences; $* \mathrm{p}<0.05 ; * * \mathrm{p}<0.01 ; * * * \mathrm{p}<0.001$.

ANOVA test is carried out to analyze if there are any differences in the relationship between $F C, P E, E E, S I, H M, P V, H A, C E I$ and $C E U$ can be attributed to the demographic variables namely age, gender, education and experience. The results show that the relationship between independent and dependent variables differ by age (5 elements: FC, PE, SI, $H M$ and $H A$ ), gender (6 elements: FC, PE, EE, SI, HA and $C E I$ ), education (5 elements: $P E, E E, S I, H M$ and $H A$ ) and experience (3 elements: $F C, E E$ and $H M$ ) are significant with $\mathrm{p}<0.05$. The results of ANOVA analysis are shown in Table 4. Although there are no differences in $P V$ and $C E U$ with demographic variables, but most of the variables are differences. Thus, H4 is supported. Generally, 7 out of 11 hypotheses are supported in this study.

The results show that facilitating condition, performance expectancy, effort expectancy, social influence, hedonic motivation, price value and habit are able to explain in both cloud-based E-learning intention nearly $60 \%\left(\mathrm{R}^{2}=0.598\right)$ and cloud-based Elearning usage about $78 \%\left(\mathrm{R}^{2}=0.781\right)$ are substantial. The results are also compared to the baseline UTAUT [47]; UTAUT2 [48] which explained roughly $56 \%$ and $40 \%$ (UTAUT); $74 \%$ and $52 \%$ (UTAUT2) of the variance in behavioral intention and technology use respectively. Research results can contribute to the theory of information system, it is not only in Vietnam but also in the globe, here user acceptance and use of cloud-based E-learning. 


\section{Conclusions}

The study illustrates that all scales of independent variables, intention of cloud-based E-learning and use of cloud-based E-learning ensure reliability. Exploratory and confirmatory factor analysis indicates that measurement scales for all constructs are satisfactory. The results also provide that are relationships between the performance expectancy, social influence, hedonic motivation, habit, and cloud-based E-learning intention, and cloud-based E-learning usage. The facilitating condition, effort expectancy, price value and habit are non-significant with cloud-based E-learning intention, and facilitating condition is non-significant with cloud-based E-learning usage. In addition, the study provides the differences in variables are attributed to the demographic. There are seven out of eleven hypotheses are supported in this research. The research model explains the behavioral intention and technology usage is better than the UTAUT [47] and UTAUT2 [48]. Which is harmonized to the context of user acceptance and use of information system.

\section{References}

1. Ajzen, I.: Behavioral Control, Self-Efficacy, Locus of Control and the Theory of Planned Behavior. Journal of Applied Social Psychology 32, 665-683 (2002)

2. Ajzen, I.: From Intentions to Action: A theory of Planned Pehavior, pp. 11-39. Springer (1985)

3. Ajzen, I.: The Theory of Planned Behavior. Organization Behavior and Human Decision Process 50, 179-211 (1991)

4. Ajzen, I., Fishbein, M.: The Influence of Attitudes on Behavior. In: Albarracin, D., Johnson, B.T., Zanna, M.P. (eds.) The Handbook of Attitudes, pp. 173-221. Erlbaum, Mahwah (2005)

5. Ajzen, I., Fishbein, M.: Understanding attitudes and predicting social behavior. Prentice Hall, Englewood Cliffs (1980)

6. Ambient Insight: Worldwide Market for Self-paced eLearning Products and Services: 2011-2016 Forecast and Analysis. Ambient Insight Report (2013),

http: / / www . ambientinsight.com

7. Bhruthari, G.P., Sanil, S.N., Prajakta, P.D.: Appliance of Cloud Computing on E-Learning. International Journal of Computer Science and Management Research, 276-281 (2012)

8. Brown, S.A., Venkatesh, V.: Model of Adoption of Technology in the Household: A Baseline Model Test and Ext. Incorporating Household Life Cycle. MIS Quarterly 29(4), 399-426 (2005)

9. Certifyme: Announces E-learning Statistics for 2013 (2013), http: / / www. certifyme.net

10. Childers, T.L., Carr, C.L., Peck, J., Carson, S.: Hedonic and Utilitarian Motivations for Online Retail Shopping Behavior. Journal of Retailing 77(4), 511-535 (2001)

11. Compeau, D.R., Higgins, C.A.: Computer self-efficacy: Development of a measure and initial test. MIS Quarterly 19(2), 189-211 (1995)

12. Davis, F.D.: Perceived usefulness, perceived ease of use and user acceptance of Information Technology. MIS Quaterly 13(3), 319-340 (1989) 
13. Davis, F.D.: User acceptance of information technology: System characteristics, user perceptions and behavioral impacts. International Journal of Man-Machine 38, 475-487 (1993)

14. Davis, F.D., Bagozzi, R.P., Warshaw, P.R.: Extrinsic and Intrinsic Motivation to Use Computers in the Workplace. Journal of Applied Social Psychology 22(14), 1111-1132 (1992)

15. Deepanshu, M., Ashish, P., Suneet, K., Arjun, A.: E-learning based on Cloud Computing. International Journal of Advanced Research in Computer Science and Software 2(2), 1-6 (2012)

16. Dodds, W.B., Monroe, K.B., Grewal, D.: Effects of Price, Brand and Store Information for Buyers. Journal of Marketing Research 28(3), 307-319 (1991)

17. Fishbein, M., Ajzen, I.: Belief, attitude, intention and behavior: An introduction to theory and research. Addision-Wesley (1975)

18. Fornell, C., Larcker, D.F.: Evaluating Structural Equation Models with unobservable variables and measurement error. Journal of Marketing Research 18(1), 39-50 (1981)

19. Hair, J.F., Black, W.C., Babin, B.J., Anderson, R.E.: Multivariate data analysis: A global perspective. Pearson, London (2010)

20. Heijden, V.D.: User Acceptance of Hedonic Information Systems. MIS Quarterly 28(4), 695-704 (2004)

21. Hill, T., Smith, N.D., Mann, M.F.: Role of efficacy expectations in predicting the decision to use advanced technologies: The case of computers. Journal of Applied Psychology 72(2), 307-313 (1987)

22. Kamel, S.: The role of virtual organizations in post-graduate education in Egypt: The case of the regional IT institute. In: Tan, F.B. (ed.) Courses on Global IT Applications and Management: Success and Pitfalls, pp. 203-224. Idea Group Publishing, Hershey (2002)

23. Kim, S.S., Malhotra, N.K., Narasimhan, S.: Two competing perspectives on automatic use: A Theoretical and Empirical Comparison. Information Systems Research 16(4), 418-432 (2005)

24. Laisheng, X., Zhengxia, W.: Cloud Computing a New Business Paradigm for E-learning. In: International Conference on Measuring Technology and Mechatronics Automation, pp. 716-719 (2011)

25. Leonardo, R.O., Adriano, J.M., Gabriela, V.P., Rafael, V.: Adoption analysis of cloud computing services. African Journal of Business Management 7(24), 2362-2374 (2013)

26. Likert: A Technique for the Measurement of Attitude. Archive Psychology 140 (1932)

27. Limayem, M., Hirt, S.G., Cheung, C.M.K.: How Habit Limits the Predictive Power of Intentions: The Case of IS Continuance. MIS Quarterly 31(4), 705-737 (2007)

28. Lin, P.C., Lu, S.C., Liu, S.K.: Towards an Education Behavioral Intention Model for ELearning Systems: an Extension of UTAUT. Journal of Theoretical and Applied Information Technology 47(3), 1120-1127 (2013)

29. Phankokkruad, M.: Implement of Cloud Computing for e-Leaming System. In: International Conference on Computer \& Information Science. IEEE (2012)

30. Masud, A.H., Huang, X.: An E-learning System Architecture based on Cloud Computing. World Academy of Science, Engineering and Technology 62, 71-76 (2012)

31. Moore, G.C., Benbasat, I.: Development of an instrument to measure the perception of adopting an information technology innovation. Information Systems Research 2(3), 192$222(1991)$

32. Muhambe, T.M., Daniel, O.O.: Post adoption evaluation model for cloud computing services utilization in universities in Kenya. International Journal of Management \& Information Technology 5(3), 615-628 (2013)

33. Nunnally, J.C., Bernstein, I.H.: Psychometric theory. McGraw Hill, New York (1994) 
34. Pocatilu, P., Alecu, F., Vetrici, M.: Using Cloud Computing for E-learning Systems. In: Recent Advances on Data Networks, Communications, Computers, pp. 54-59 (2009)

35. Pocatilu, P., Alecu, F., Vetrici, M.: Cloud Computing Benefits for E-learning Solutions. Economics of Knowledge 2(1), 9-14 (2010)

36. Rogers, E.M.: Diffusion of innovations. Free Press, New York (1995)

37. Sheppard, B.H., Hartwick, J., Warshaw, P.R.: The Theory of Reasoned Action: A MetaAnalysis of Past Research with Recommendations for Modifications and Future Research. Journal of Consumer Research 15(3), 325-343 (1988)

38. Soud, A., Fisal, A.R.: Factors that determine continuance intention to use e-learning system: an empirical investigation. In: International Conference on Telecommunication Technology and Applications, vol. 5, pp. 241-246. IACSIT Press, Singapore (2011)

39. Sun Microsystem: Cloud Computing Guide. Sun Microsystems Inc. (2009)

40. Sun, P., Tsai, R., Finger, G., Chen, Y., Yeh, D.: What drives a successful e-Learning? An empirical investigation of the critical factors influencing learner satisfaction. Computers \& Education 50, 1183-1202 (2008)

41. Tavangarian, D., Leypold, M.E., Nolting, K., Roser, M., Voigt, D.: Is e-Learning the solution for individual learning? Electronic Journal of e-Learning 2(2), 273-280 (2004)

42. Taylor, S., Todd, P.: Understanding Information Technology Usage: A Test of Competing Models. Information Systems Research 6(2), 144-176 (1995)

43. Thompson, R., Higgins, R., Howell, L.: Personal computing: Toward a conceptual model of utilization. MIS Quarterly 15(1), 125-143 (1991)

44. Utpal, J.B., Majidul, A.: E-Learning using Cloud Computing. International Journal of Science and Modern Engineering, 9-13 (2013)

45. Venkatesh, V.: Determinants of Perceived Ease of Use: Integrating Perceived Behavioral Control, Computer Anxiety and Enjoyment into the Technology Acceptance Model. Information Systems Research 11(4), 342-365 (2000)

46. Venkatesh, V., Davis, F.D.: A Theoretical Extension of the Technology Acceptance Model: Four Longitudinal Field Studies. Management Science 46(2), 186-204 (2000)

47. Venkatesh, V., Morris, M.G., Davis, G.B., Davis, F.D.: User acceptance of information technology: Toward a unified view. MIS Quarterly 27(3), 425-478 (2003)

48. Venkatesh, V., Thong, Y.L.J., Xin, X.: Consumer Acceptance and Use of Information Technology: Extending the Unified Theory of Acceptance and Use of Technology. MIS Quarterly 36(1), 157-178 (2012)

49. Venkatraman Archana: Italian university reduces costs by $23 \%$ with cloud platform (2013), http: / / www . computerweekly . com

50. Vietnam Ministry of Education and Training: The guide about deployment task for the academic year of 2011-2012. Dispatch no. 4960/GDĐT-CNTT (2011)

51. Viswanath, K., Kusuma, S., Gupta, S.K.: Cloud Computing Issues and Benefits Modern Education. Global Journal of Computer Science and Technology Cloud \& Distributed 12(10), 1-7 (2012)

52. Will, M., Allan, Y.: E-learning system Acceptance and usage pattern. In: Technology Acceptance in Education: Research and Issue, pp. 201-216 (2011)

53. Zaharescu, E.: Enhanced Virtual E-Learning Environments Using Cloud Computing Architectures. International Journal of Computer Science Research and Application 2(1), 3141 (2012)

54. Zeithaml, V.A.: Consumer Perceptions of Price, Quality, and Value: A Means-End Model and Synthesis of Evidence. Journal of Marketing 52(3), 2-22 (1988)

55. Zheng, H., Jingxia, V.: Integrating E-Learning System Based on Cloud Computing. In: International Conference on Granular Computing. IEEE (2012) 